\title{
BMJ Open A nationwide population-based cohort study of peripartum hysterectomy and arterial embolisation in Belgium: results from the Belgian Obstetric Surveillance System
}

\author{
Griet Vandenberghe, ${ }^{1}$ Marine Guisset, ${ }^{2}$ Iris Janssens, ${ }^{3}$ Virginie Van Leeuw, ${ }^{4,5}$ \\ Kristien Roelens, ${ }^{1}$ Myriam Hanssens, ${ }^{2}$ Erika Russo, ${ }^{6}$ Joachim Van Keirsbilck, ${ }^{7}$ \\ Yvon Englert, ${ }^{4,8}$ Hans Verstraelen ${ }^{1}$
}

To cite: Vandenberghe $\mathrm{G}$, Guisset M, Janssens I, et al. A nationwide population-based cohort study of peripartum hysterectomy and arterial embolisation in Belgium: results from the Belgian Obstetric Surveillance System. BMJ Open 2017;7:e016208. doi:10.1136/ bmjopen-2017-016208

- Prepublication history and additional material for this paper are available online. To view these files please visit the journal online (http://dx.doi. org/10.1136/bmjopen-2017016208).

Received 14 March 2017 Revised 6 June 2017 Accepted 7 June 2017

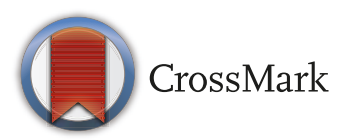

For numbered affiliations see end of article.

Correspondence to

Griet Vandenberghe;

griet.vandenberghe@uzgent.be

\section{ABSTRACT}

Objectives To assess the prevalence of major obstetric haemorrhage managed with peripartum hysterectomy and/or interventional radiology (IR) in Belgium. To describe women characteristics, the circumstances in which the interventions took place, the management of the obstetric haemorrhage, the outcome and additional morbidity of these women.

Design Nationwide population-based prospective cohort study.

Setting Emergency obstetric care. Participation of $97 \%$ of maternities covering $98.6 \%$ of deliveries in Belgium.

Participants All women who underwent peripartum hysterectomy and/or IR procedures in Belgium between January 2012 and December 2013.

Results We obtained data on 166 women who underwent peripartum hysterectomy $(\mathrm{n}=84)$ and/or IR procedures $(n=102)$, corresponding to 1 in 3030 women undergoing a peripartum hysterectomy and another 1 in 3030 women being managed by $I R$, thereby preserving the uterus. Seventeen women underwent hysterectomy following IR and three women needed further IR despite hysterectomy. Abnormal placentation and/or uterine atony were the reported causes of haemorrhage in $83.7 \%$. Abnormally invasive placenta was not detected antenatally in $34 \%$ of cases. The interventions were planned in 15 women. Three women were transferred antenatally and 17 women postnatally to a hospital with emergency IR service. Urgent peripartum hysterectomy was averted in $72 \%$ of the women who were transferred, with no significant difference in need for transfusion. IR procedures were able to stop the bleeding in $87.8 \%$ of the attempts. Disseminated intravascular coagulation secondary to major haemorrhage was reported in 32 women (19\%). Conclusion The prevalence in Belgium of major obstetric haemorrhage requiring peripartum hysterectomy and/ or IR is estimated at 6.6 (95\% Cl 5.7 to 7.7$)$ per 10000 deliveries. Increased clinician awareness of the risk factors of abnormal placentation could further improve the management and outcome of major obstetric haemorrhage. A case-by-case in-depth analysis is necessary to reveal whether the hysterectomies and
Strengths and limitations of this study

- This is a nationwide study of Belgian maternities, with excellent participation and response rates (98.8\%). The cases were collected on a monthly basis using the standard methodology of obstetric surveillance systems.

- This study describes how women with major obstetric haemorrhage were managed with peripartum hysterectomy and/or interventional radiology according to circumstances.

- The study lacks a perspective on the overall picture of postpartum haemorrhage in Belgium, namely the total number of women suffering severe postpartum haemorrhage, near-misses or death due to postpartum haemorrhage.

- The study lacks denominator data of the women with postpartum haemorrhage who were successfully managed with other second-line measures. Therefore we cannot draw conclusions on the failure rate of intrauterine balloon tamponade, haemostatic brace suturing and ligation of the uterine arteries.

arterial embolisations performed in this study were appropriate or preventable.

\section{BACKGROUND}

Emergency peripartum hysterectomy is the single most dramatic procedure in modern obstetrics. The procedure is stressful and surgically challenging, inevitably causing additional maternal morbidity and, not least, infertility. It is listed by the WHO as an identification criterion for maternal nearmiss, ${ }^{1}$ a concept that, in view of the very low maternal mortality rates in developed country settings, ${ }^{2}$ was introduced as an analytical tool to address health system failures with the overall goal of improving obstetric care. ${ }^{3}$ 
Substandard care in the management of major obstetric haemorrhage continues to be a critical cause of maternal death and severe maternal morbidity in developed countries. ${ }^{45}$ Every obstetric practitioner needs to be trained in the management of postpartum haemorrhage in order to guarantee an immediate response and a multidisciplinary team approach. Internationally recognised guidelines $^{6-8}$ indicate that one or more second-line measures, including intrauterine (balloon) tamponade, haemostatic brace suturing, ligation of the uterine arteries and interventional radiology (IR), should be available in hospitals with delivery units and that obstetric practitioners should be familiar with these procedures. Notably, the early involvement of an experienced senior obstetrician, hence appropriate clinical judgement, can save lives: the timely decision to turn to a hysterectomy can avoid further blood loss, risk of disseminated intravascular coagulation (DIC), additional morbidity and finally death. ${ }^{6}$

While emergency peripartum hysterectomy serves as the ultimate response to major obstetric haemorrhage, resorting to IR procedures on the pathway towards hysterectomy can be both life-saving and fertility-preserving. IR in this context basically involves intra-arterial balloon occlusion or arterial embolisation of the uterine or the internal iliac arteries. Research publications on the effectiveness of IR procedures in obstetric settings reporting high success rates of $85 \%-95 \%$ are accumulating. ${ }^{9-12}$ Success rates should be interpreted with caution, however, as they may be driven by ascertainment bias. IR is cautiously suggested in guidelines and recommendations $^{6-8} 1314$ describing its possible role in obstetric emergency settings, but further evidence is awaited before firm recommendations can be made. Yet in the UK a national recommendation was made to provide a network of emergency IR services available to all trusts with delivery units in response to a Healthcare Commission Investigation into maternal deaths. ${ }^{1315}$

The aims of this study are to investigate the population-based prevalence of peripartum hysterectomy and the indications to proceed to this intervention, likewise the prevalence of major obstetric haemorrhage managed with IR in Belgium. Furthermore, we aim to describe the characteristics of the women in Belgium who required these interventions in order to treat or prevent major obstetric haemorrhage, the circumstances in which the interventions took place, the management of the obstetric haemorrhage and the outcome and additional morbidity of these women.

\section{METHOD}

\section{Belgian Obstetric Surveillance System}

Peripartum hysterectomy and IR in Belgium were registered as part of a national reporting system for the study of rare obstetric complications. The methodology of the Belgian Obstetric Surveillance System (B.OSS) has been described previously. ${ }^{16}$ Briefly, an appointed contact person (obstetrician or senior midwife) in each participating maternity unit was invited by monthly mailing to report a selected number of rare obstetric complications that had occurred in the preceding month or, alternatively, to state that there was 'nothing to report'. In the event of such a case being reported, the contact person was asked to complete an extensive data collection form. Confidentiality was guaranteed for mother, provider and hospital, and person-identifiable information was eliminated from data analysis. In cases of incomplete reporting, the appointed contact person was encouraged repeatedly by email and phone to provide the missing data, up to 6 months following the date of the original report.

The participation of $97 \%$ of Belgian maternity units $(\mathrm{n}=110 / 113)$ was obtained, covering $98.6 \%$ of deliveries $(\mathrm{n}=248681)$ in the 2-year study period. Belgium has a relatively large number of tertiary referral centres providing neonatal intensive care $(n=19)$ along with a high concentration of small-volume maternity units (more than half of all units) in which there are fewer than 1000 annual births. All tertiary referral centres, as well as some of the larger non-tertiary maternity services, have an emergency IR service. In answer to an enquiry of B.OSS contact persons, 40 maternity units (38\%) declared they had an IR service available in the hospital, and a further seven units declared that they had an IR service available but not $24 / 7$ or that they could call on vascular surgeons for similar procedures.

\section{Study period}

The study was conducted between January 2012 and December 2013.

\section{Case definition}

B.OSS aimed to collect all cases of peripartum hysterectomy and IR at any gestational age corresponding to the following definition: any woman giving birth to a fetus or infant and undergoing a hysterectomy and/or IR procedure in the same clinical episode. Most peripartum hysterectomies are emergency, life-saving interventions following vaginal or caesarean delivery, most commonly performed to manage major obstetric haemorrhage but occasionally because of a severe pelvic infection. Hysterectomy in the first or second trimester, termed abortion hysterectomy, is occasionally required to prevent or manage major obstetric haemorrhage resulting from an abnormally invasive placenta (AIP) or an ectopic pregnancy in the cornua, the cervix or a caesarean scar. A peripartum hysterectomy during caesarean delivery $(\mathrm{CD})$, termed 'caesarean hysterectomy', can be performed electively following antenatal diagnosis of a severe AIP or a gynaecological cancer.

Failure of IR was defined as the need for urgent peripartum hysterectomy to control the haemorrhage.

\section{Registered variables}

Data collection forms sought information on maternal characteristics, medical, surgical and obstetric history, 
details of the index pregnancy, details of the delivery, the circumstances of the adverse event, its management, and the outcome for mother and neonate.

The cause of the obstetric haemorrhage was deduced from the clinical signs reported by the clinician and classified according to the 4T's mnemonic: tonus, tissue, trauma and thrombin. These labels were taken to stand for the following characteristics: tonus: uterine atony; tissue: AIP, placenta praevia, combination of AIP and placenta praevia, placental remnants or retained placenta without AIP; trauma: uterine rupture, genital tract lacerations, bleeding caused by unintended injuries during caesarean delivery or curettage (uncomplicated CDs were not included in this category); and thrombin: abnormal coagulation before onset of bleeding (DIC secondary to major haemorrhage was not included in this category). Cases where the cause of bleeding remained unclear or unknown were classified as 'Other'.

\section{Registered variables of the background population}

The Belgian perinatal registries - Studiecentrum voor Perinatale Epidemiologie (SPE) in Flanders, ${ }^{17} 18$ and Centre d'Epidémiologie Périnatale in Brussels ${ }^{19}$ and Wallonia ${ }^{20}$ - record data on a mandatory basis, covering nearly $100 \%$ of births in Belgium. A selected set of perinatal data are recorded by the obstetrician, midwife and neonatologist immediately after birth. Births are registered as such in cases of a live birth or in cases of a stillbirth at a birth weight of $500 \mathrm{~g}$ or more and/or after 22 completed weeks of gestation, although in Flanders (SPE) live births or stillbirths with a birth weight below $500 \mathrm{~g}$, irrespective of gestational age, are not registered.

\section{Statistical analysis}

The aim was to record all cases of peripartum hysterectomy and arterial embolisation during a 2-year study period, meaning that no fixed sample size was set at start of the study. The prevalence of the obstetric events targeted was estimated using as denominator the total number of deliveries in Belgium in 2012 and 2013, corrected for the three hospitals that did not participate in B.OSS ( $n=248681$ women). Comparison of the distributions of sociodemographic and obstetric characteristics of reported cases relative to the background population as obtained from the Belgian perinatal registry (2012-2013) was pursued through use of ORs. ORs and accompanying $95 \%$ CI were calculated in univariate analysis, using weighted cases where appropriate. Unadjusted and adjusted ORs were calculated in order to compare patient and organisational characteristics between interventions (hysterectomy vs IR) in univariate analysis and subsequently through the use of unconditional binary logistic regression models. Comparison between successful and failed IR cases was made only in crude analyses, as numbers of observations were too small to support logistic regression models.

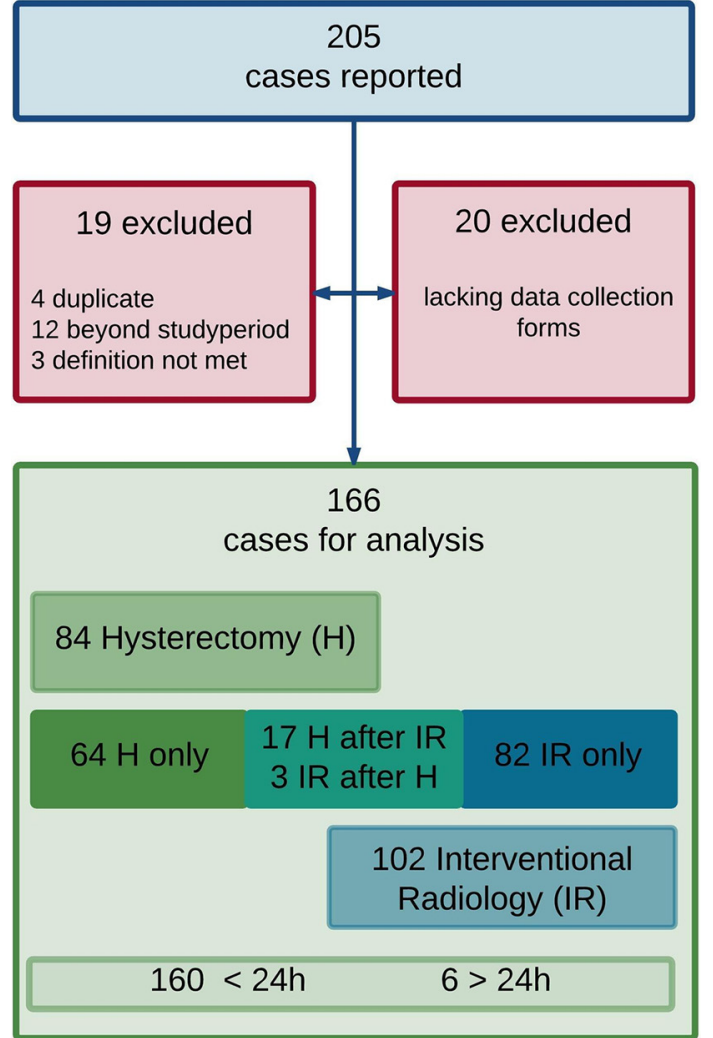

Figure 1 Flow chart of case reporting and data collection.

Non-parametric tests were used to compare distributions of outcomes between groups, specifically $\chi^{2}$ for categorical variables, and Kruskal-Wallis and MannWhitney $\mathrm{U}$ tests for continuous variables. p Values of $<0.05$ were considered statistically significant. Data were analysed using the statistical software package IBM SPSS V.22.0 statistics. $^{21}$

The Strengthening the Reporting of Observational Studies in Epidemiology guidelines for reporting observational studies were followed.

\section{RESULTS \\ Prevalence}

Data collection forms of 166 confirmed cases of peripartum hysterectomy and/or IR were retrieved and included in the analysis. Details of reported cases and completeness of data collection forms are presented in figure 1 .

Overall, 84 women $(50.6 \%)$ underwent a peripartum hysterectomy, corresponding to a prevalence of 3.3 per 10000 deliveries (95\% CI 2.7 to 4.1$)$. Of these, 17 women $(10.2 \%)$ underwent a hysterectomy following a previous IR procedure. Eighty-two women $(49.4 \%)$ were managed with IR only, corresponding to a prevalence of 3.3 per 10000 deliveries $(95 \%$ CI 2.6 to 4.0$)$. Three women $(1.8 \%)$ needed IR because of persistent bleeding despite hysterectomy.

In 160 women the intervention occurred within 24 hours of delivery. In eight women it occurred later 
(from 24 hours to 6 weeks postpartum). The discrepancy between the resultant sum of 168 and the 166 figure above is because two of the data collection forms were not returned, one of these being the only case in this data set of a hysterectomy performed because of severe peritonitis. All other women underwent hysterectomy and/or IR to treat or prevent major obstetric haemorrhage. The prevalence in Belgium of major obstetric haemorrhage requiring peripartum hysterectomy and/or IR is estimated at 6.6 (95\% CI 5.7 to 7.7) per 10000 deliveries.

\section{Patient characteristics}

We compared the women included in this registry with all the women who gave birth in Belgium during the study period. Patient characteristics of the background population were derived from the Belgian perinatal registries. In univariate analysis the women who underwent peripartum hysterectomy and/or IR for major obstetric haemorrhage were significantly more likely compared with the background population to be older ( $\geq 35$ years), to be multiparous (parity $\geq 3$ ), to have given birth at a preterm gestational age, to have had a twin pregnancy, to have had a CD in a previous pregnancy, to have had a $\mathrm{CD}$ in the index pregnancy and to have conceived with artificial reproductive technology (table 1). Ten of these 166 women were known to have a uterus myomatosus $(6.0 \%)$ and 12 experienced haemorrhage in a previous pregnancy $(7.2 \%)$.

\section{Circumstances of the obstetric haemorrhage}

IR service availability, antenatal and postnatal transfers, and urgent and planned interventions

The circumstances in which the interventions occurred in these 166 women are shown in figure 2 . Three women were transferred antenatally to another hospital with emergency IR service availability, a total of 107 women gave birth in a maternity unit with this availability, while

Table 1 Patient characteristics of women with (imminent) obstetric haemorrhage who underwent peripartum hysterectomy and/or IR compared with all women who gave birth in Belgium during the study period

\begin{tabular}{|c|c|c|c|}
\hline Risk factor & $\begin{array}{l}\text { Cases of } H \text { and/or IR } \\
(n=166) n, \%\end{array}$ & $\begin{array}{l}\text { Background population* } \\
(n=252272) n, \%\end{array}$ & $\begin{array}{l}\text { Unadjusted OR† for } \mathrm{H} \\
\text { and/or IR }(95 \% \mathrm{Cl})\end{array}$ \\
\hline Maternal age $\geq 35$ years & $72(43.4)$ & $43256(17.1)$ & $3.7(2.7 \text { to } 5.0)^{\star \star}$ \\
\hline $\mathrm{BMI}$ at booking $\geq 30 \mathrm{~kg} / \mathrm{m}^{2}$ & $12(7.2) \emptyset$ & $29453(11.6)$ & $0.7(0.3$ to 1.2$)$ \\
\hline Gestational age (weeks) & $\begin{array}{l}\text { Singletons } \geq 22 \text { weeks } \\
(n=144)\end{array}$ & $\begin{array}{l}\text { Singletons } \geq 22 \text { weeks } \\
(n=241136)\end{array}$ & \\
\hline Extreme preterm $(<28)$ & $8(5.4)$ & $1221(0.5)$ & $7.4(5.3 \text { to } 10.5)^{\star \star}$ \\
\hline Late preterm(32-37 weeks) & $37(24.8)$ & $13798(5.7)$ & \\
\hline Term $(>37)$ & $93(62.4)$ & $224643(93.1)$ & Reference \\
\hline Parity $\geq 3$ & $30(18.0)$ & $18855(7.4)$ & $2.7(1.8 \text { to } 4.1)^{\star \star}$ \\
\hline Multiplets (twin) & $13(7.8)$ & $4690(1.8)$ & $4.4(2.5 \text { to } 7.9)^{\star \star}$ \\
\hline Previous CD $\ddagger$ & $61(36.7) \uparrow$ & $27007(10.7)$ & $4.8(3.5 \text { to } 6.6)^{\star *}$ \\
\hline $\begin{array}{l}\text { CD before onset of labour compared with CD after } \\
\text { onset of labour }\end{array}$ & $66 / 91(72.5)$ & $28586 / 54369(52.5)$ & $2.3(1.5$ to 3.7$)$ \\
\hline Assisted VD compared with spontaneous VD & $10 / 69(14.4)$ & 23 100/198444 (11.6) & $1.3(0.6$ to 2.5$)$ \\
\hline ART (IVF/ICSI) & $19(11.4) \Re$ & $9233(3.7)$ & $3.4(2.1 \text { to } 5.4)^{\star \star}$ \\
\hline Birth weight $\geq 4000 \mathrm{~g}$ & $11(6.6)$ & 19967 (7.8) & $0.8(0.4$ to 1.5$)$ \\
\hline
\end{tabular}

Reason for CD: bleeding (placenta praevia, AIP, abruptio placentae): $n=15$; placenta praevia/AIP not bleeding: $n=29$; maternal shock/cardiac arrest: $n=1$; Other: $n=46$.

${ }^{*}$ Data from the background population were retrieved from SPE reports (Flanders) and CEpiP reports (Brussels and Wallonia) from 2012 to 2013.

†Unadjusted ORs (with 95\% Cl) for peripartum hysterectomy and/or IR calculated for the different risk factors: the odds (=probability of peripartum hysterectomy and/or IR occurring divided by the probability of H/IR not occurring) in the women having the risk factor, divided by the odds in the women not having the risk factor.

$¥$ Women with CD as delivery mode: 17 with placenta praevia, 8 with AIP, and 23 with placenta praevia and AIP.

§Women with previous CD: 9 with placenta praevia, 9 with AIP, and 17 with placenta praevia and AIP.

१Missing data in cases of hysterectomy and/or IR: BMI $(n=27)$, previous CD $(n=1)$, mode of delivery $(n=1)$, ART ( $n=2)$, haemorrhage in previous pregnancy $(n=5)$, uterus myomatosus $(n=5)$.

${ }^{* *} \mathrm{p}<0.05$.

AIP, abnormally invasive placenta; ART, artificial reproductive technologies; BMI, body mass index; CD, caesarean delivery; CEpiP; Centre d'Epidémiologie Périnatale; H, hysterectomy; ICSI, intracytoplasmic sperm injection; IR, interventional radiology; IVF, in vitro fertilisation; SPE, Studiecentrum voor Perinatale Epidemiologie; TOLAC, trial of labour after caesarean delivery; VD, vaginal delivery. 


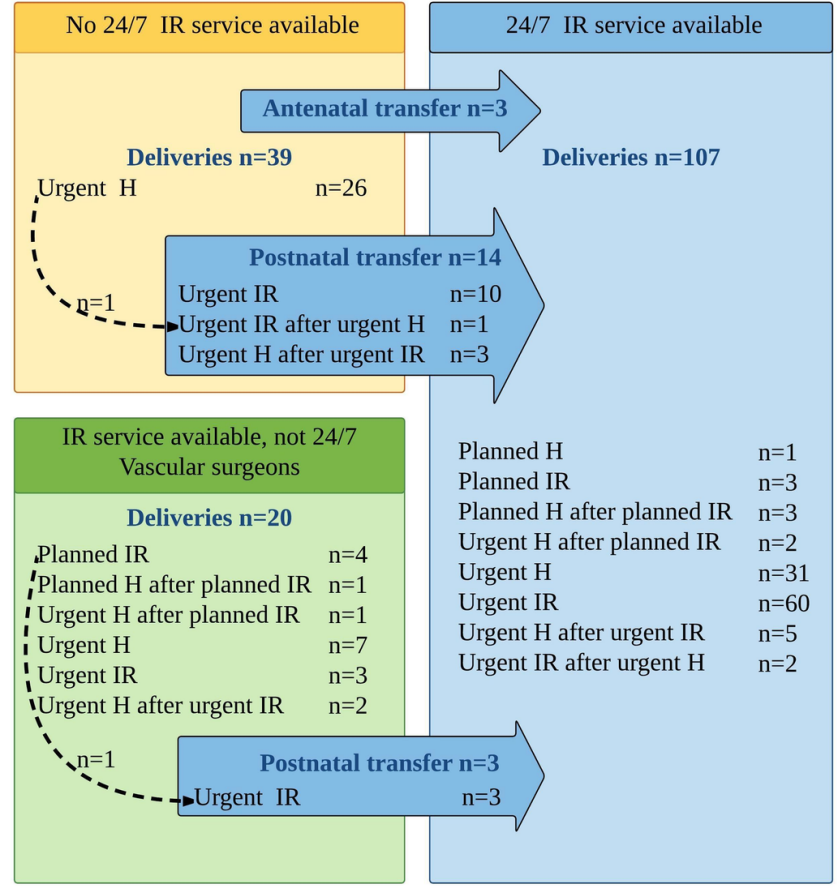

R: interventional radiology. H: hysterectomy

Figure 2 Circumstances in which peripartum hysterectomy and interventional radiology occurred in 166 women.

20 gave birth in a unit where IR service is available but not $24 / 7$ or where obstetricians can call on vascular surgeons for IR procedures, and 39 in a unit with no IR service. To refer to these different circumstances below, we use the terms 24/7-IR unit, not 24/7-IR unit and non-IR unit, respectively.

Seventeen women were transferred postnatally to a 24/7-IR unit and underwent an urgent IR procedure, including one woman for persistent bleeding despite hysterectomy and one woman for persistent bleeding despite planned intra-arterial balloon occlusion and arterial embolisation by the vascular surgeons in the referring hospital. Three of the postnatally transferred women consecutively underwent an urgent hysterectomy for persistent bleeding despite arterial embolisation.

Of the three patients who were transferred antenatally, one underwent an urgent embolisation on arrival because of a bleeding placenta praevia, one was first planned for caesarean hysterectomy but then underwent this procedure urgently because of a bleeding AIP before the fixed date, and one underwent a planned CD combined with a planned IR procedure because of AIP. Seven more women were transferred postnatally to the intensive care unit (ICU) of a tertiary referral centre.

Overall, intervention for imminent obstetric haemorrhage was planned in 15 women. The indication was AIP in 13 women and placenta praevia in 2 women.

Reported cause of the obstetric haemorrhage

Eighteen women $(11 \%)$ presented with antepartum haemorrhage due to abnormal placentation (placenta praevia, AIP or both) or abruptio placentae $(n=2)$. Four women $(2 \%)$ started bleeding during termination of

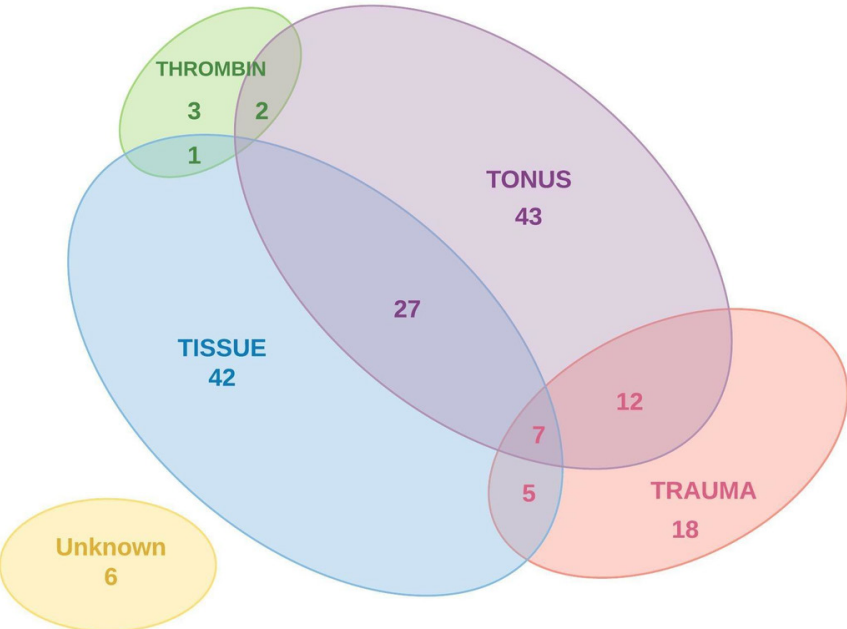

Figure 3 Cause of obstetric haemorrhage according to the 4T's mnemonic.

pregnancy ( $<24$ weeks) due to a cervical pregnancy $(\mathrm{n}=1)$ or an AIP $(n=3)$. One hundred and thirty-eight women $(83 \%)$ presented with early postpartum haemorrhage (within 24 hours) and six (4\%) with late postpartum haemorrhage (from 24 hours to 6 weeks).

The reported cause of the obstetric haemorrhage was uterine atony $(\mathrm{n}=91,54.8 \%)$ or AIP $(\mathrm{n}=38,22.8 \%)$ in the majority of women. In 54 women $(32.5 \%)$ more than one cause was reported, with atony and abnormal placentation (AIP and/or placenta praevia) in 20 women (12\%) as the most frequent combination. The cause of the (imminent) obstetric haemorrhage classified according to the $4 \mathrm{~T}$ 's mnemonic is shown in figure 3 .

\section{Management of the obstetric haemorrhage}

Hysterectomy was performed in all the cases of haemorrhage reported to be associated with uterine rupture $(n=12)$ and in $73.7 \%$ of the cases associated with AIP $(n=28 / 38)$. IR was able to stop the bleeding and avert the need for peripartum hysterectomy in the majority of cases of haemorrhage reported to be associated with genital tract lacerations $(\mathrm{n}=10 / 12,83.3 \%)$, placental remnants or retention $(\mathrm{n}=17 / 26,65.4 \%)$ and uterine atony $(\mathrm{n}=28 / 43,65.1 \%)$.

Other measures that were attempted to manage the obstetric haemorrhage before or while proceeding to the hysterectomy or IR are listed in table 2. The first-line measures were the administration of uterotonic agents and bimanual uterine compression, second-line measures being intra-uterine (balloon) tamponade, haemostatic brace suturing (B-lynch or other) and ligation of the uterine or internal iliac arteries, besides blood transfusion and the administration of fresh frozen plasma (FFP), platelets or clotting factors. An intra-uterine balloon was inserted in 35 women (21\%), in 7 cases before transfer to another hospital with availability of an IR service. Brace suturing and arterial ligation were attempted in 6 and 4 women, respectively. In 19 women $(11.4 \%)$ no other measures were undertaken besides hysterectomy $(n=13)$, IR $(n=2)$ or hysterectomy 
Table 2 First-line and second-line measures in women undergoing hysterectomy $(\mathrm{H})$ and/or interventional radiology (IR) according to the circumstances of the obstetric haemorrhage

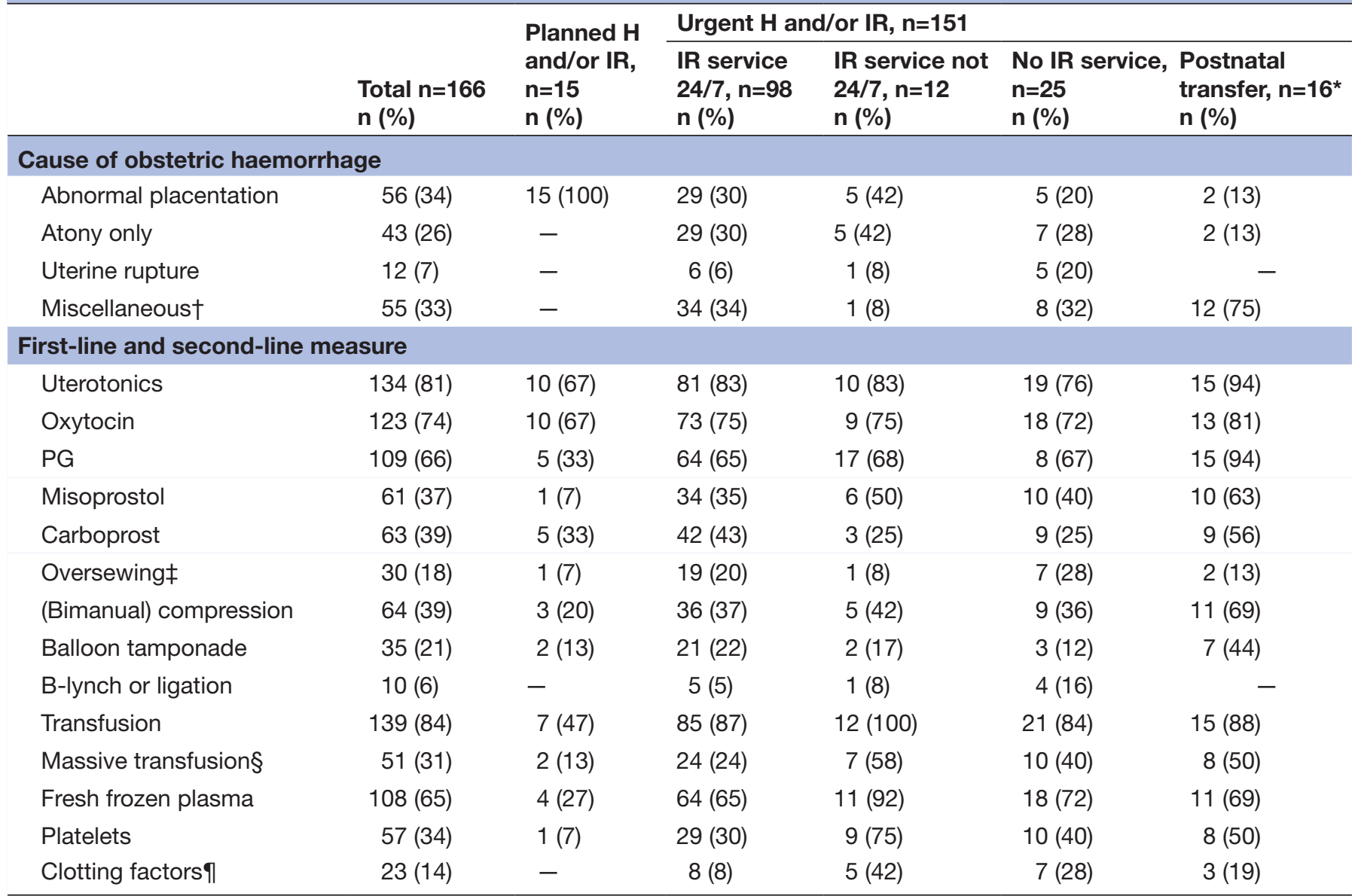

${ }^{*}$ One woman was transferred postnatally for persistent bleeding due to abnormally invasive placenta despite planned IR in the referring hospital; she was included in the 'planned' group.

†Miscellaneous group: placental remnants or retention $n=25$, surgical trauma $n=16$, genital tract laceration $n=11$, intra-abdominal arterial bleeding $n=4$, coagulation disorders $n=3$, unknown $n=6$. The total number exceeds $n=55$ due to overlap in between cases.

$\ddagger$ Oversewing of the placental implantation site, bleeding points, tears or ruptures.

§Massive transfusion: transfusion of 8 or more units of red blood cells.

ПClotting factors: fibrinogen, recombinant factor VIla, prothrombin-proconvertin-Stuart factor-antihaemophilic factor B, or a combination.

PG, prostaglandin. This can be any or a combination of the following: misoprostol, sulprostone, dinoprostone, carboprost.

following IR $(n=4)$. The reported cause of haemorrhage in these women was AIP $(n=12)$, placenta praevia $(n=2)$, uterine rupture $(n=2)$, retained placenta $(n=2)$ and in one case a late postpartum haemorrhage. The intervention was planned in five of these women. Eight of the 19 had minor haemorrhage and did not require transfusion, while three women undergoing urgent peripartum hysterectomy needed massive transfusion (defined as receiving eight or more units of red blood cells (RBCs)).

\section{Management of AIP}

The management of the (imminent) obstetric haemorrhage in the women with AIP $(n=38)$ is illustrated in figure 4 (for details see online supplementary figure 1 ). Seventeen women $(45 \%)$ were susceptible to AIP due to previous $\mathrm{CD}$ and placenta praevia in the index pregnancy, another seven women (18\%) had placenta praevia in the index pregnancy and nine women (24\%) had previous CD. In 25 women $(65.7 \%)$ there was antenatal suspicion of the AIP, of whom 16 had placenta praevia and previous $\mathrm{CD}, 5$ had placenta praevia and 4 had previous CD only. All women with antenatal suspicion of AIP were planned to undergo an elective $\mathrm{CD}$ in a maternity unit with IR service availability $(24 / 7 n=20$, not $24 / 7 n=5)$. This occurred in 21 women, with 3 women having an emergency CD because of antepartum haemorrhage and 1 woman delivering vaginally following acute onset of labour. Further preventive measures were undertaken in 13 women $(31.5 \%)$ : antenatal transfer to a centre with IR service availability $(n=2)$, placement of intra-arterial catheters precaesarean delivery $(n=12)$, planned caesarean hysterectomy $(n=3)$ or planned hysterectomy at a later stage $(\mathrm{n}=2)$.

In 13 women (34\%) there was no antenatal suspicion of the AIP. In retrospect, though, all of them had risk factors: one woman had placenta praevia and previous $\mathrm{CD}$, four had placenta praevia, six had previous CD, one had previous myomectomy and adhesiolysis for Asherman 


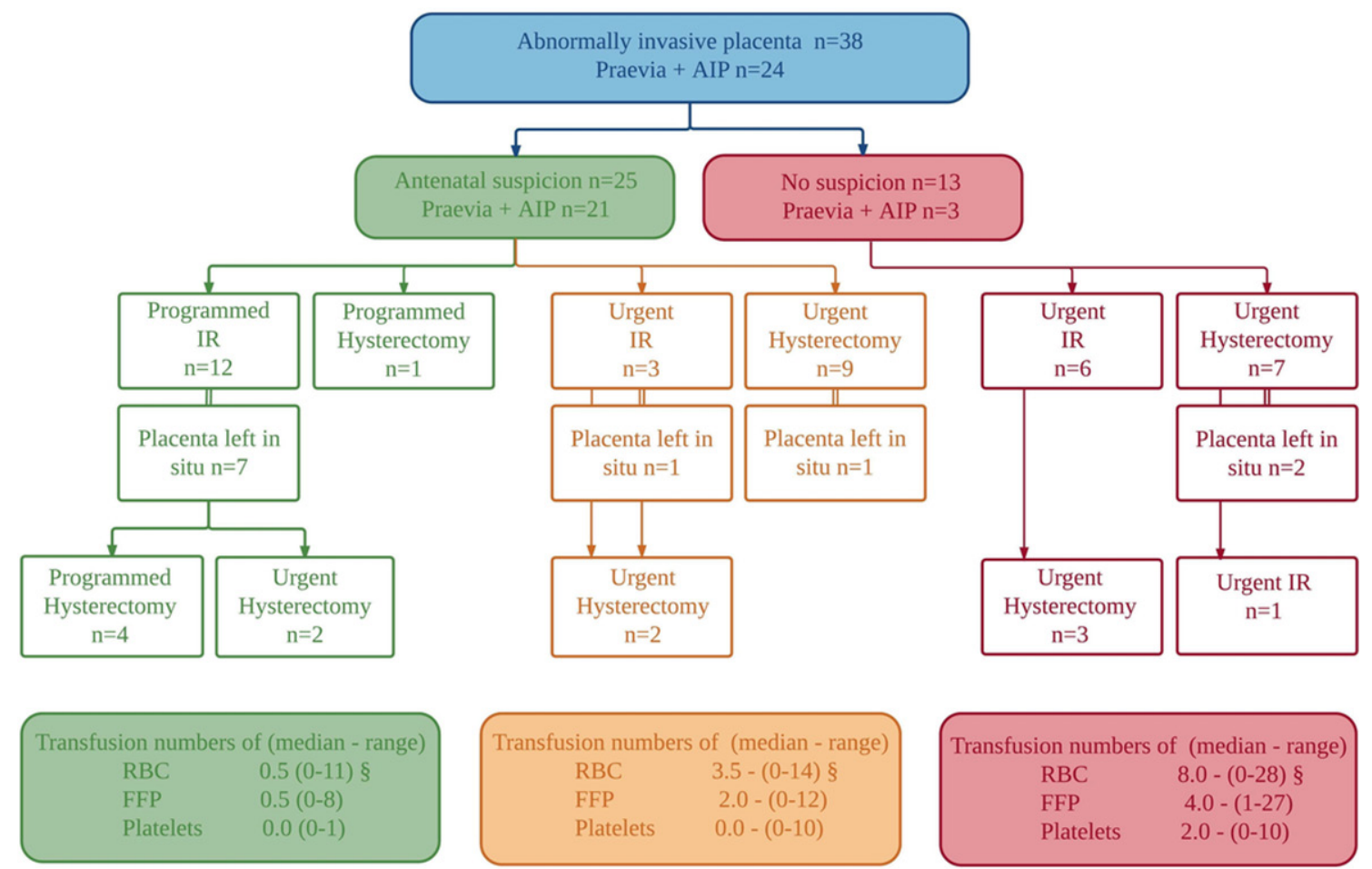

Figure 4 Antenatal suspicion and preventive measures in women with AIP. AIP, abnormally invasive placenta; FFP, fresh frozen plasma; IR, interventional radiology; RBC, red blood cells.

syndrome and another had a previous manual removal of the placenta. Nine women delivered in a maternity unit with IR service availability $(24 / 7 \mathrm{n}=7$, not $24 / 7 \mathrm{n}=2)$ and four delivered in a non-IR unit. The mode of delivery in those 13 women who had no antenatal suspicion of AIP was elective $\mathrm{CD}$ in two women, emergency $\mathrm{CD}$ in five women and vaginal delivery in six women.

The placenta was left in situ in 11 women with AIP: four in an emergency setting where three women underwent immediate hysterectomy and one woman underwent urgent arterial embolisation followed by urgent hysterectomy because of bleeding after 3 days. Another seven women had their placenta left in situ electively combined with planned IR: two women consecutively underwent planned hysterectomy, two an urgent hysterectomy within 24 hours, two a planned hysterectomy after 1 month, and one elective evacuation of retained products of conception after 1 month. In conclusion, conservative management, defined as aiming to preserve the placenta and the uterus in a multidisciplinary approach, was attempted in six women and was successful in three women.

As anticipated, the women for whom measures were planned antenatally had significantly better outcomes than those where AIP was diagnosed peripartum: less estimated blood loss (median $625 \mathrm{~mL}$ (range $300-1250$ ) vs median $4500 \mathrm{~mL}$ (range $500-6000$ ), $\mathrm{p}=0.08$ ), less need for transfusion ( $46.2 \%$ vs $92.3 \%, \mathrm{p}=0.056$ ), less need for massive transfusion ( $\geq 8$ units) ( $8.3 \%$ vs $53.8 \%, \mathrm{p}=0.045)$ and fewer hysterectomies $(61.5 \%$ vs $76.9 \%, p=0.6)$. The maternal outcome was not significantly different between women with AIP undergoing IR as first intervention and those with hysterectomy as first intervention: estimated blood loss (median $4000 \mathrm{~mL}$ (range 500-15000) vs median $1000 \mathrm{~mL}$ (range $300-8500), \mathrm{p}=0.3$ ), need for transfusion $(76.5 \%$ vs $70 \%, \mathrm{p}=0.9$ ) and need for massive transfusion ( $\geq 8$ units) $(29.4 \%$ vs $30 \%, \mathrm{p}=1.0)$. All women with planned interventions were managed in tertiary referral centres.

\section{Risk factors possibly contributing to the choice of intervention}

The decision of an obstetrician dealing with a major obstetric haemorrhage to attempt IR rather than turning to a hysterectomy immediately will be guided by many clinical and organisational factors. Some of the risk factors that may have contributed to this decision are presented in table 3 . The women with double interventions $(n=20)$ were excluded from this analysis to facilitate interpretation.

High parity $(\geq 3)$, previous $\mathrm{CD}, \mathrm{CD}$ in the index pregnancy, AIP and lack of emergency IR service availability are significantly positively associated with peripartum hysterectomy in univariate analysis. In unconditional binary logistic regression, the odds of undergoing a hysterectomy for obstetric haemorrhage are 7.2 times higher in women with high parity and 8.2 times higher in women delivering in a non-IR unit, independent of the other risk factors in the model (Hosmer and Lemeshow test $\mathrm{p}=0.67$ ).

We repeated the analysis in a subgroup, namely the women who delivered in a $24 / 7$-IR unit, with exclusion of the women with planned interventions, consisting of 31 women who underwent hysterectomy only and 60 women who underwent embolisation only. In unconditional binary logistic regression, the odds of undergoing a peripartum hysterectomy for obstetric haemorrhage 
Table 3 Risk factors possibly contributing to the choice of intervention in women undergoing hysterectomy or interventional radiology for obstetric haemorrhage, unadjusted and adjusted OR $(95 \% \mathrm{Cl})$ for hysterectomy (only) per risk factor

\begin{tabular}{|c|c|c|c|c|}
\hline \multirow[b]{2}{*}{ Risk factors } & \multicolumn{2}{|c|}{ Number of women } & \multirow{2}{*}{$\begin{array}{l}\text { Unadjusted OR } \\
(95 \% \mathrm{Cl}) \text { for } \\
\text { hysterectomy only }\end{array}$} & \multirow{2}{*}{$\begin{array}{l}\text { Adjusted OR } \\
(95 \% \mathrm{Cl}) \text { for } \\
\text { hysterectomy onl }\end{array}$} \\
\hline & $\begin{array}{l}\text { Hysterectomy } \\
\text { only, } n=64 n, \%\end{array}$ & $\begin{array}{l}\text { Interventional radiology } \\
\text { only, } n=82 n, \%\end{array}$ & & \\
\hline \multicolumn{5}{|l|}{ Demographic factors } \\
\hline Maternal age $\geq 35$ years & $32(50.0)$ & $30(36.5)$ & 1.7 (0.8 to 3.3$)$ & \\
\hline $\begin{array}{l}\text { Body mass index at booking } \\
\geq 30 \mathrm{~kg} / \mathrm{m}^{2}\end{array}$ & $6(9.3)$ & $3(3.6)$ & 2.7 (0.6 to 11.3$)$ & \\
\hline \multicolumn{5}{|l|}{ Obstetric factors } \\
\hline Preterm (<37 weeks) & $28(43.8)$ & $24(29.3)$ & 1.8 (0.9 to 3.7$)$ & \\
\hline Parity $\geq 3$ & $18(28.1)$ & $7(8.5)$ & $2.7(1.4$ to 9.4$) \S$ & $7.2(2.1$ to 24.6$) \S$ \\
\hline Previous caesarean delivery $\emptyset$ & $31(48.4)$ & $18(21.9)$ & 3.3 (1.6 to 6.8$) \S$ & 2.3 (0.9 to 6.3$)$ \\
\hline Caesarean delivery $(\geq 22 \text { weeks })^{*} \emptyset$ & $38 / 59(64.4)$ & $37 / 82(45.1)$ & $2.2(1.1$ to 4.3$) \S$ & $1.6(0.6$ to 4.0$)$ \\
\hline \multicolumn{5}{|c|}{ Cause of bleeding } \\
\hline AIP and AIP+praeviaף & $16(25.0)$ & $9(10.9)$ & $2.7(1.1$ to 6.6$) \S$ & $3.0(0.9$ to 10.0$)$ \\
\hline Atony & $29(45.3)$ & $52(63.4)$ & $0.4(0.2$ to 0.9$) \S$ & 0.9 (0.3 to 2.3$)$ \\
\hline \multicolumn{5}{|l|}{ Organisational factors } \\
\hline $\begin{array}{l}\text { Weekend and/or non-office } \\
\text { hourstף }\end{array}$ & $24 / 60(40.0)$ & $34 / 80(42.5)$ & $0.9(0.4$ to 1.7$)$ & \\
\hline $\begin{array}{l}\text { Interventional radiology NOT } \\
\text { available } \neq\end{array}$ & $30(46.8)$ & 15 (18.2) & 3.9 (1.8 to 8.2$) \S$ & 8.2 (3.1 to 21.6$) \S$ \\
\hline
\end{tabular}

${ }^{*}$ Exclusion of 5 cases $<22$ weeks.

†Based on date and time of delivery.

‡Emergency interventional radiology service availability in the maternity unit where the woman gave birth.

$\S \mathrm{p}<0.05$.

१Missing data: body mass index $(n=27)$, previous caesarean delivery $(n=1)$, delivery mode $(n=1)$, placenta location $(n=13)$, date of delivery $(n=2)$, time of delivery $(n=5)$, week/weekend $(n=3)$.

AIP, abnormally invasive placenta.

are significantly higher in women with high parity (odds 4.5 (95\% CI 1.2 to 16.5$)$ ) and nearly significantly higher in women with previous CD (odds 3.7 (95\% CI 0.98 to 14.6)), independent of the other risk factors in the model (Hosmer and Lemeshow test $\mathrm{p}=0.69$ ).

\section{Peripartum hysterectomy despite IR}

Seventeen women in this data set had a peripartum hysterectomy performed following a previous IR procedure. In five of these women the hysterectomy was performed in a programmed setting following planned IR because of AIP, two of them with a delay of 1 month. These five IR procedures were considered successful in preventing or stopping the bleeding. In the other 12 women, an urgent hysterectomy was performed because of persistent bleeding despite the IR procedure. We compared the characteristics of these 12 women for whom IR failed with 87 women (including the 5 who underwent an elective hysterectomy) for whom IR was successful. In univariate analysis, an increased risk of urgent hysterectomy despite IR was observed for women with $\mathrm{CD}$ in a previous pregnancy, for women with AIP and for women who had no uterotonic agents administered. These findings are presented in table 4.

\section{Maternal outcome and additional morbidity}

Blood transfusion was given to 139 women $(83.7 \%$, missing data for 2 women), with a median of 6.0 units of RBCs (range 0-31), 4.0 units of FFP (range 0-31) and 0.5 units of platelets (range 0-29). Fifty-one women (30.7\%) were transfused $\geq 8$ units of RBC and 23 women were administered clotting factors (fibrinogen, recombinant factor VIIa, prothrombin-proconvertin-Stuart factor-antihaemophilic factor B or a combination). One hundred and fourteen women $(68.6 \%$, missing data in 4 women) were admitted to an ICU for a median of 2.0 days (range 0-18 days); the median hospital stay was 8.0 days (range 2-33 days). Five women needed relaparotomy and three women needed arterial embolisation following hysterectomy because of persistent bleeding. The cause of haemorrhage in these women was AIP $(\mathrm{n}=1)$, AIP and atony $(n=2)$, atony $(n=3)$ and in 1 case unclear $(n=1)$.

DIC secondary to major haemorrhage was reported in 32 women $(19 \%)$. Other reported maternal complications associated with major haemorrhage were renal failure $(n=2)$, pulmonary oedema $(n=4)$, acute respiratory distress syndrome $(n=2)$, myocardial ischaemia $(n=1)$ and pleural and pericardial effusion $(\mathrm{n}=1)$. Complications associated with peripartum hysterectomy were ureteral 
Table 4 Risk factors possibly contributing to failure of IR, unadjusted ORs $(95 \% \mathrm{CI})$ for failed IR per risk factor

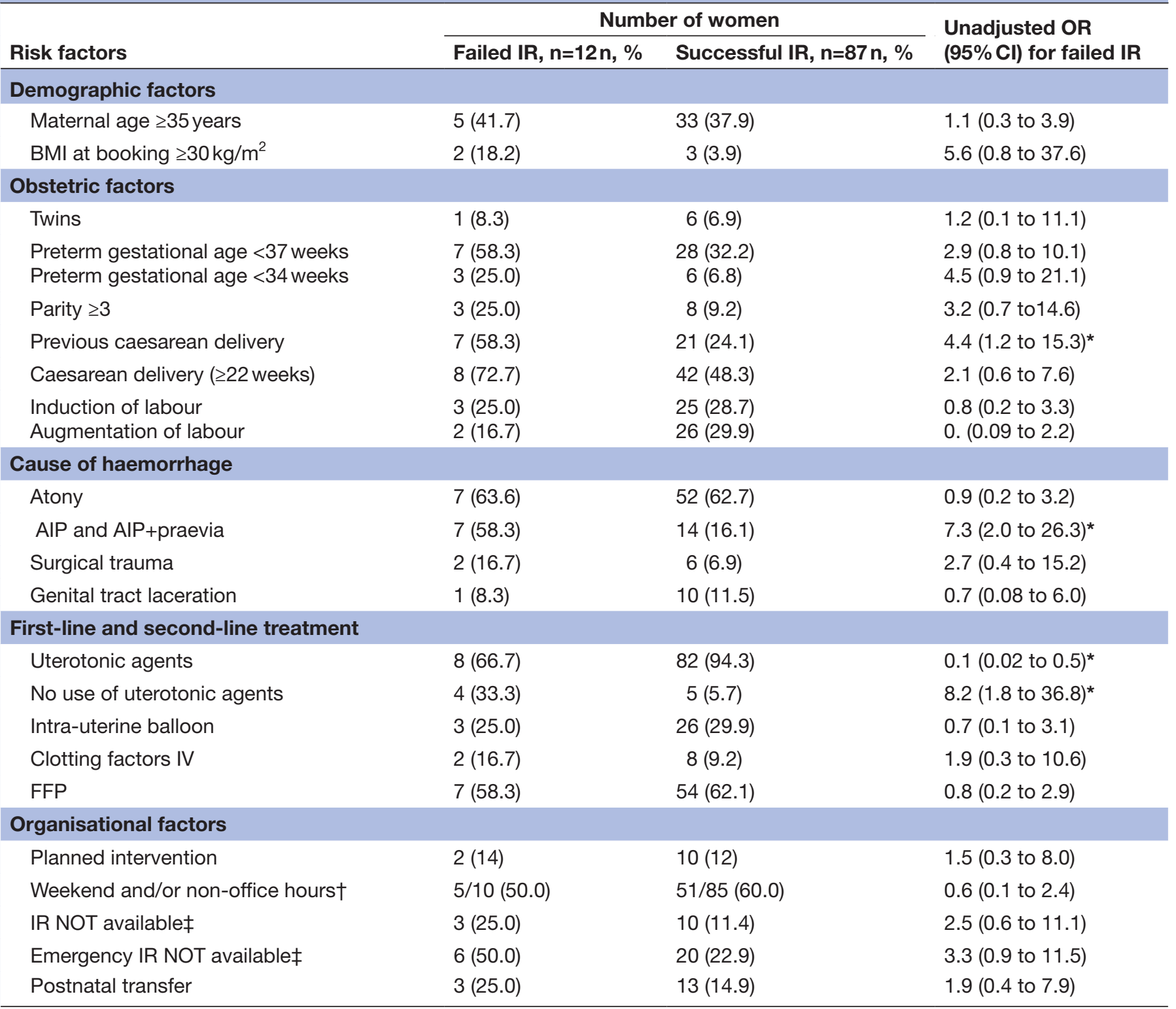

${ }^{*} \mathrm{p}<0.05$.

†Based on date and time of delivery.

fIR service availability (24/7 and not $24 / 7)$ in the maternity unit where the woman gave birth.

fEmergency IR service availability (24/7) in the maternity unit where the woman gave birth.

AIP, abnormally invasive placenta; BMI, body mass index; FFP, fresh frozen plasma; IR, interventional radiology.

injuries $(n=2)$ and ileus $(n=4)$. One woman suffered from pain in the loins and legs, which was the only reported complication attributed to the IR procedure.

One mother died (case fatality rate $0.6 \%$ (95\% CI 0.1 to 3.3)). She underwent an emergency CD because of cardiac arrest caused by massive pulmonary embolism. She survived the hysterectomy performed because of major bleeding due to uterine atony and was transferred to the ICU of a tertiary referral centre using extracorporeal life support. She underwent a relaparotomy because of major hepatic haemorrhage, but died the subsequent day during pulmonary thrombectomy.

Considering the whole group, the outcome in terms of transfusion rate and ICU admission in women who underwent hysterectomy did not significantly differ from those who underwent IR, except for a significant difference in total duration of hospitalisation (median 9 days, range (2-30) vs median 7 days (range 2-33)). When comparing the women according to the IR service availability in the maternity unit where they gave birth, the rate of peripartum hysterectomy was significantly higher in the group of women who delivered in a non-IR unit (29 women $(74 \%)$ ) than in the group who delivered in a 24/7-IR unit (44 women, $41 \%$ ), and so was the rate of massive transfusion (defined as $\geq 8$ units of RBC): 17 women (45\%) who delivered in a non-IR unit compared with 25 women $(24 \%)$ who delivered in a 24/7-IR unit. 
When comparing the women who gave birth in a non-IR unit according to whether they were transferred postpartum, there was no significant difference in estimated blood loss (median $2850 \mathrm{~mL}$ (range $500-5000$ ) vs median $3500 \mathrm{~mL}$ (range 3000-5000), $\mathrm{p}=0.4$ ) and need for transfusion (median number of units 6.5 (range 0-19) vs 9.5 (range $0-31$ ), $\mathrm{p}=0.2$ ), but all women who were not transferred $(\mathrm{n}=25 / 25)$ underwent a hysterectomy compared with $28 \%(n=4 / 14)$ in the transferred group $(\mathrm{p}=0.0)$.

\section{DISCUSSION}

The main findings of this study are, first, that the prevalence in Belgium of major obstetric haemorrhage requiring peripartum hysterectomy and/or IR is estimated at 6.6 (95\% CI 5.7 to 7.7) per 10000 deliveries; second, that AIP was not detected antenatally in $34 \%$ of the cases in this study, despite the presence of risk factors; third, that women with major obstetric haemorrhage who gave birth in a non-IR unit were more likely to undergo an urgent peripartum hysterectomy $(74 \%)$ than those who delivered in a 24/7-IR unit (41\%); and fourth, that the need for urgent peripartum hysterectomy was averted in $72 \%$ of the women who delivered in a non-IR unit but transferred postnatally, with no significant difference in estimated blood loss and transfusion rate compared with the women who were not transferred.

The strengths of the study are its methodology of collecting cases prospectively on a monthly basis and its national design, with excellent participation and response rates $(98.9 \%)$ of Belgian maternity units. Under-reporting of cases, due to the non-mandatory reporting of severe pregnancy complications, may have biased our results to some extent. The small number of cases, inevitable with rare but severe obstetric complications, warrants caution in making strong inferences. Another limitation is the lack of a perspective on the overall picture of postpartum haemorrhage in Belgium. We have no accurate data of the total number of women suffering severe postpartum haemorrhage, the near-misses and maternal deaths due to severe haemorrhage who did not undergo embolisation or hysterectomy. We have no denominator data of the women who were successfully managed with other second-line measures (intra-uterine (balloon) tamponade, haemostatic brace suturing and ligation of the uterine arteries) during the same study period in Belgium, so we cannot draw conclusions on the failure rate of these second-line measures. These are interesting topics that can be investigated by B.OSS in future studies.

This nationwide population-based study describes how women with major obstetric haemorrhage were managed with either hysterectomy or IR according to circumstances. However, this study does not allow firm conclusions to be drawn regarding the motivation or the appropriateness of this management. One should be aware that obstetricians are forced to make rapid decisions when dealing with a major obstetric haemorrhage. Belgian obstetricians cannot rely on national guidelines for postpartum haemorrhage or AIP. Small volume maternity units even lack local hospital guidelines for these matters. Therefore, the management of major obstetric haemorrhage will differ greatly between hospitals and individual obstetricians. An emergency IR service is available in about $38 \%$ of Belgian maternity units, complemented with an informal network between hospitals as shown in the data set: 20 women (12\%) were transferred to a centre with IR availability. We cannot rule out the possibility that this study in fact demonstrates an overuse of IR procedures and underuse of other second-line measures in the management of postpartum haemorrhage in Belgium. This reasonable hypothesis has been previously suggested by Kayem $e t a l^{22}$ based on the results of a population-based study of women with postpartum haemorrhage managed with invasive therapies in France.

The use of peripartum hysterectomy was significantly higher in multiparous women (parity $\geq 3$ ) and in women who delivered in a non-IR unit. This result may not surprise, and performing a hysterectomy sooner rather than later must be considered good practice, ${ }^{6}$ as losing time trying another second-line measure can cause further blood loss and further morbidity. The decision is more easily made in cases of women who have no desire for continued fertility. Likewise, the transfer of a haemodynamically unstable patient to an IR service is hardly ever considered a safe alternative if this IR service is located in a nearby hospital. However, the higher rate of massive blood transfusion in the group of women who delivered in a non-IR unit strengthens the hypothesis that the rate of hysterectomy is associated with the IR service availability and with the expert knowledge and experience at larger units in the management of massive obstetric haemorrhage. A case-by-case in-depth analysis would be necessary to reveal whether the hysterectomies and arterial embolisations recorded in this study were appropriate or preventable. A structured audit based on medical records of 50 peripartum hysterectomies was recently performed in Denmark. This population-based audit revealed that more than $50 \%$ of peripartum hysterectomies were avoidable by simple measures such as the use of intrauterine balloons. ${ }^{23}$

AIP accounts for $23 \%$ of the interventions and $86 \%$ of the planned interventions in this data set. Targeted papers report good sensitivity and positive predictive value (PPV) of greyscale ultrasound as the screening tool for AIP in women with a high index of suspicion, enhanced by the use of transvaginal ultrasound and colour Doppler. ${ }^{24}{ }^{25}$ Nonetheless, the diagnosis of AIP was missed antenatally in $34 \%$ of the women in this study, although all of them had risk factors that should have increased awareness. Several population-based studies report rather low antenatal diagnosis rates of AIP: $50 \%$ of AIP cases were missed in a study of the UK Obstetric Surveillance System, even though 30\% of these missed cases had a previous $\mathrm{CD}$ and placenta praevia. ${ }^{26}$ Similarly, in the Nordic Obstetric Surveillance Study, $70 \%$ of AIP cases were missed, despite the fact that $33 \%$ had placenta praevia and $39 \%$ had previous $\mathrm{CD} .{ }^{27} \mathrm{In}$ 
view of these findings, we believe that antenatal diagnosis of AIP may be improved by raising the awareness of clinicians of the risk factors for AIP. This involves actively asking for previous uterine surgery at the first antenatal visit, checking the position of the placenta and focused imaging in the pregnancies at risk. ${ }^{28}$ Importantly, there is little information about the sensitivity or PPV of ultrasound or MRI as the screening tool for AIP in women who have had no previous uterine surgery or in women in whom the placenta is not implanted anteriorly in the lower uterine segment, ${ }^{24}$ which would be an interesting topic for future research. Despite increased awareness a number of cases of abnormal placentation will still be missed. For this reason, all maternity units should ensure a state of constant preparedness to deal with an unanticipated AIP, which causes a major haemorrhage at any time.

Although numbers are small, this study aligns with the findings in previous studies that maternal outcome is better when women with suspicion of AIP give birth in specialised tertiary centres and when preventive measures are taken. ${ }^{2629} 30$ A planned preterm caesarean hysterectomy with the placenta left in situ is the indubitable treatment of choice in women with AIP and is incorporated in recommendations of the Royal College of Obstetricians and Gynaecologists (RCOG) ${ }^{14}$ the American College of Obstetricians and Gynecologists (ACOG) $)^{31}$ and the Society for Maternal-Fetal Medicine (SMFM). ${ }^{32}$ Alternatively, a conservative approach is advocated for women who want to preserve their fertility and are haemodynamically stable, which means a multidisciplinary approach aiming to leave the placenta in situ and to preserve the uterus. ${ }^{334}$ This study demonstrates that conservative management of AIP is not well incorporated in obstetric care in Belgium. The placenta was left in situ in 11 women with AIP (29\%) in this data set. A conservative approach was attempted in six women and was successful in three women. Two of these women underwent a planned hysterectomy delayed until 1 month after the CD. A small number of papers support this management (leaving the placenta in situ with a planned delayed hysterectomy) in women who have a placenta percreta with infiltration in the bladder and/or other surrounding tissues and therefore a high risk of haemorrhage or adjacent tissue injury, ${ }^{34-36}$ the rationale being that this delay will allow the decrease of the periuterine vascularisation and thus prevent haemorrhage. Studies with larger numbers are needed to strengthen evidence for the claim that this methodology is safer than caesarean hysterectomy in women with severe placenta percreta.

The role of IR in the management of AIP is still a matter of debate. Most guidelines agree that IR can be life-saving in the treatment of major postpartum haemorrhage. ${ }^{1432}$ They currently do not recommend the routine use of preoperative placement of intra-arterial catheters to enable balloon occlusion or arterial embolisation before caesarean hysterectomy or conservative treatment of AIP, based on lack of evidence of benefit. ${ }^{1431} 3237$ Meanwhile, the number of papers reporting benefit of prophylactic IR is growing. ${ }^{38}$ Our population-based study reports diverse management of women with AIP, inherent to a multicentre study. Twelve women with AIP were managed with programmed IR, the need for hysterectomy being averted in six of them. We cannot draw firm conclusions on the success rate of IR in the elective setting because of small numbers and lack of controls.

This study has demonstrated a high success rate $(87.8 \%)$ of IR in controlling postpartum haemorrhage, consistent with the success rates ranging between $85 \%$ and $95 \%$ reported by others. ${ }^{9-12} 40-42$ Univariate analysis (taking into account the small numbers) showed IR was more likely to fail in women with a $\mathrm{CD}$ in a previous pregnancy (failure rate $25 \%$ ), women with AIP (33\%) and women who had no uterotonic agents administered (44\%). Several large, hospital-based, retrospective studies have analysed the predictive factors associated with failure of IR in the management of postpartum haemorrhage. ${ }^{12}{ }^{40-43}$ Most papers report a lower success rate of IR in women with AIP, ${ }^{4041}$ which explains to a great extent the lower success rates in women with previous $\mathrm{CD}$ and in women with $\mathrm{CD}$ in the current pregnancy. $\mathrm{A}$ population-based study in the Netherlands ${ }^{10}$ reported a $25 \%$ failure rate for IR following $\mathrm{CD}$ in the current pregnancy, compared with just $16 \%$ in this study and barely $10 \%$ in a large study reported by Lee et al $(\mathrm{n}=176) .{ }^{44}$ Other researchers have consistently reported a higher failure rate of IR in women with various clinical determinants related to major haemorrhage: haemodynamic shock, ${ }^{43} 45$ diffuse intravascular coagulopathy, ${ }^{12}{ }^{45}$ low fibrinogen and prothrombin time, ${ }^{41}$ and the need for massive transfusion. ${ }^{1240} 41$ However, these factors could be either cause or consequence of the failure of IR, which was not clearly differentiated in some of the aforementioned studies. Interestingly, hospital-to-hospital transfer was not associated with a higher failure rate of IR in this study, consistent with what has been reported by others. ${ }^{12} 404$

\section{CONCLUSION}

The prevalence in Belgium of major obstetric haemorrhage requiring peripartum hysterectomy and/or IR is estimated at 6.6 (95\% CI 5.7 to 7.7$)$ per 10000 deliveries: roughly 1 in 3030 women who give birth in Belgium undergoes a peripartum hysterectomy, while another 1 in 3030 women is successfully managed by IR, thereby preserving the uterus. Abnormal placentation and/or uterine atony are reported as the cause of haemorrhage and reason for intervention in the majority of these women $(83.7 \%)$. Further improvement in the management of obstetric haemorrhage could possibly be achieved by increased awareness of risk factors for abnormal placentation on the part of clinicians and by antenatal transfer to tertiary centres in case of suspicion. A case-by-case in-depth analysis is necessary to reveal whether the hysterectomies and arterial embolisations performed in this study were appropriate or preventable.

Author affiliations

${ }^{1}$ Department of Obstetrics and Gynaecology, Ghent University Hospital, Ghent, Belgium 
${ }^{2}$ Department of Obstetrics and Gynaecology, Leuven University Hospital, Leuven, Belgium

${ }^{3}$ Faculty of Medicine, Ghent University, Ghent, Belgium

${ }^{4}$ Perinatal Epidemiology Center (Centre d'Épidémiologie Périnatale, CEpiP), School of Public Health, Université Libre de Bruxelles (ULB), Brussels, Belgium

${ }^{5}$ Université Libre de Bruxelles (ULB), School of Public Health, Brussels, Belgium ${ }^{6}$ Department of Obstetrics and Gynaecology, Intercommunale de Santé Publique du Pays de Charleroi (ISPPC), Hôpital Civil Marie Curie, Charleroi, Belgium ${ }^{7}$ Department of Obstetrics and Gynaecology, St Jan's Hospital, Bruges, Belgium ${ }^{8}$ Faculty of Medicine, Research Laboratory on Human Reproduction, Université Libre de Bruxelles (ULB), Brussels, Belgium

Acknowledgements This study would not have been possible without the voluntary participation of the following Belgian maternity units: GZA Sint-Jozef, Mortsel; GZA Sint-Augustinus, Wilrijk; GZA Sint-Vincentius, Antwerpen; ZNA, SintErasmus, Borgerhout; ZNA, Jan Palfijn, Merksem; ZNA, Middelheim, Antwerpen; ASZ, campus Aalst; ASZ, campus Geraardsbergen; AZ Lokeren; Imelda Ziekenhuis, Bonheiden; Sint-Jozef ziekenhuis, Bornem; AZ Klina, Brasschaat; AZ Sint-Jan, Brugge; AZ Sint-Lucas, Assebroek; Centre de Santé des Fagnes; Centre Hospitalier de l'Ardenne; Centre Hospitalier EpiCura, site Hornu; Centre Hospitalier de Mouscron; Centre Hospitalier du Bois de l'Abbaye et de Hesbay; Centre Hospitalier Peltzer, La Tourelle; CHC Saint-Vincent; CHC Saint-Joseph; CHC Sainte-Elisabeth; CHIREC, Clinique Sainte-Anne, Saint-Remi; CHIREC Braine-l'Alleud-Waterloo; CHR de la Citadelle; CHR de Namur; CHR du Val de Sambre; CHR Haute Senne-Le Tilleriau; CHR Mons Clinique Saint-Joseph; CHU Ambroise Paré; CHU Brugmann; CHU Charleroi, André Vésale; CHU Notre-Dame des Bruyères; CHU Saint-Pierre; CHU Tivoli; CHwapi-Site Notre-Dame; Clinique Edith Cavell; Clinique et Maternité Sainte Elisabeth; Clinique Notre dame de Grâce; Clinique Reine Astrid; Clinique SaintePiere; Cliniques de l'Europe, Saint-Michel; Cliniques de l'Europe, SainteElisabeth; Cliniques du Sud Luxembourg; Cliniques Universitaires Saint-Luc; AZ SintVincentius, Deinze; AZ Sint-Blasius, Dendermonde; AZ Monica, Deurne; AZ Diest; AZ Sint-Maarten, Duffel; AZ Alma, Eeklo; Dimpna Ziekenhuis, Geel; AZ Jan Palfijn, Gent; AZ Maria Middelares, Gent; AZ Sint-Lucas, Gent; GHDC - Notre Dame, Charleroi; AZ Maria ziekenhuis, Halle; Jessaziekenhuis, Hasselt; AZ Sint Elisabeth, Herentals; CAZ Midden-Limburg, Heusden-Zolder; Hôpital Civil Marie Curie; Hôpital Erasme, Bruxelles; Hôpitaux Iris Sud - Site Ixelles; Jan Yperman ziekenhuis, leper; IFAC Hôpital Princesse Paola; INDC Entité Jolimontoise; Sint-Jozef ziekenhuis, Izegem; Kliniek Sint-Jan; Klinik Saint-Josef; AZ Zeno, campus KnokkeHeist; AZ Groeninge, Kortrijk; Heilig Hart ziekenhuis, Leuven; UZ Leuven; Heilig Hart ziekenhuis, Lier; AZ Sint-Jozef, Malle; AZ Sint-Maarten, Mechelen; AZ Delta, campus Menen; Heilig Hart ziekenhuis, Mol; Onze-Lieve-Vrouw ziekenhuis, campus Aalst; Onze-LieveVrouw ziekenhuis, campus Asse; AZ Damiaan, campus Sint-Jozef, Oostende; AZ Sint-Jan, campus Oostende; AZ Oudenaarde; Mariaziekenhuis NoordLimburg, Overpelt; AZ Heilige Familie, Reet AZ Delta, campus Brugsesteenweg, Roeselare; AZ Delta, campus Wilgenstraat, Roeselare; AZ Glorieux, Ronse; AZ Nikolaas, Sint-Niklaas; Sint-Trudo ziekenhuis, Sint-Truiden; Saint-Nikolaus Hospital; SintAndries ziekenhuis, Tielt; Heilig Hartziekenhuis, Tienen; AZ Vesalius, Tongeren; Sint-Rembertziekenhuis, Torhout; AZ Turnhout; UZ Antwerpen; UZ Brussel; AZ SintAugustinus, Veurne; AZ Jan Portaels, Vilvoorde; Onze-Lieve-Vrouw van Lourdes ziekenhuis, Waregem; Ziekenhuis Oost-Limburg, campus Sint-Jan, Genk; AZ SintElisabeth, Zottegem. We would like to thank Fatima Bercha, Marlies Deblaere and Ann Langedock for their contribution in collecting the data.

Contributors Project conception: MH, YE. Study design: GV, VVL, JV, MH, YE. Data collection: GV, MG, IR, VVL, JV. Data analysis: GV, MG, IJ, ER. Data interpretation: GV, MG, IJ, KR, MH, ER, YE, HV. Manuscript first draft: GV. Contributed to the writing of the manuscript: MG, IJ, KR, MH, YE, HV. Manuscript revision: MG, IJ, VVL, KR, MH, ER, JV, YE, HV. All authors approved the final version, agreed to be accountable for all aspects of the work and met the ICMJE criteria for authorship.

Funding The study was funded by the College for Mother and Newborn, a consultative body of the Belgian Public Health Service. GV was funded by the Flemish Research Foundation (FW0).

Competing interests All authors have completed the ICMJE uniform disclosure form at www.icmje.org/coi_disclosure.pdf and hereby declare that they have no financial relationships with any organisations that might have an interest in the submitted work in the past 3 years, nor that they have partaken of any other relationships or activities that could appear to have influenced the submitted work.

Patient consent Data were retrieved in retrospect from the case notes by means of data collection forms. No personally identifiable information was obtained. Participants were informed and enabled to opt-out.
Ethics approval Medical Ethics Committee of the Ghent University Hospital.

Provenance and peer review Not commissioned; externally peer reviewed.

Data sharing statement There are no additional unplished data from the study available.

Open Access This is an Open Access article distributed in accordance with the Creative Commons Attribution Non Commercial (CC BY-NC 4.0) license, which permits others to distribute, remix, adapt, build upon this work non-commercially, and license their derivative works on different terms, provided the original work is properly cited and the use is non-commercial. See: http://creativecommons.org/ licenses/by-nc/4.0/

(c) Article author(s) (or their employer(s) unless otherwise stated in the text of the article) 2017. All rights reserved. No commercial use is permitted unless otherwise expressly granted.

\section{REFERENCES}

1. Evaluating the quality of care for severe pregnancy complications: the WHO near-miss approach for maternal health. Switzerland: Geneva, 2011. Retrieved fromAccessed. http://apps.who.int/iris/bitstream/ 10665/44692/1/9789241502221 eng.pdf.

2. Stones W, Lim W, Al-Azzawi F, et al. An investigation of maternal morbidity with identification of life-threatening 'near miss' episodes. Health Trends 1991;23:13-15.

3. Say L, Souza JP, Pattinson RC. WHO working group on Maternal Mortality and Morbidity classifications. Maternal near miss--towards a standard tool for monitoring quality of maternal health care. Best Pract Res Clin Obstet Gynaecol 2009;23:287-96.

4. Lewis G. The Confidential Enquiry into Maternal and Child Health (CEMACH). Saving Mother's Lives: reviewing maternal deaths to make motherhood safer-2003-2005. The Seventh Report on Confidential Enquiries into Maternal Deaths in the United Kingdom. London: CEMACH, 2007.

5. In: Knight M, Tuffnell D, Kenyon S, Kenyon S, Shakespear J, Gray R, Kurinczuk JJ, et al. eds. On behalf of MBRRACE-UK. saving lives, improving mother's Care - Surveillance of maternal deaths in the UK 2011-13 and lessons learned to inform maternity care from the UK and Ireland Confidential Enquiries into Maternal Deaths and Morbidity 2009-13. Oxford: National Perinatal Epidemiology Unit, University of Oxford, 2015.

6. The Royal College of Obstetricians and Gynaecologists. Postpartum Haemorrhage, Prevention and Management. Green-top Guideline No. 52. Published: 11/05/2009.

7. Hemorrhage P. The American College of Obstetricians and Gynaecologistis. ACOG Practice Bulletin. Number, 2006.

8. Dahlke JD, Mendez-Figueroa H, Maggio L, et al. Prevention and management of postpartum hemorrhage: a comparison of 4 national guidelines. Am J Obstet Gynecol 2015;213:e1-10:76.

9. Kayem G, Kurinczuk JJ, Alfirevic Z, et al. Specific second-line therapies for postpartum haemorrhage: a national cohort study. BJOG 2011;118:856-64.

10. Zwart JJ, Dijk PD, van Roosmalen J. Peripartum hysterectomy and arterial embolization for major obstetric hemorrhage: a 2-year nationwide cohort study in the Netherlands. Am J Obstet Gynecol 2010;202 :e1-7:150

11. Inoue S, Masuyama H, Hiramatsu Y. Multi-Institutional Study Group of Transarterial Embolization for Massive Obstetric Haemorrhage in Chugoku \& Shikoku Area Society of Obstetrics and Gynecology. Efficacy of transarterial embolisation in the management of postpartum haemorrhage and its impact on subsequent pregnancies. Aust N Z J Obstet Gynaecol 2014;54:541-5.

12. Lee HY, Shin JH, Kim J, et al. Primary postpartum hemorrhage: outcome of pelvic arterial embolization in 251 patients at a single institution. Radiology 2012;264:903-9.

13. The Royal College of Obstetricians and Gynaecologists. the role of emergency and elective interventional radiology in postpartum haemorrhage. 6, 2007.

14. The Royal College of Obstetricians and Gynaecologists. Placenta Praevia, Placenta Praevia Accreta and Vasa Praevia : Diagnosis and Management. Green-top Guideline No. 27. Published January 2011.

15. Commission for Healthcare Audit and Inspection. Investigation into 10 maternal deaths at, or following delivery at, Northwick Park Hospital, North West London Hospitals NHS Trust, between April 2002 and April 2005. London, 2006.

16. Vandenberghe G, De Blaere M, Van Leeuw V, et al. Nationwide population-based cohort study of uterine rupture in Belgium: results from the Belgian Obstetric Surveillance System. BMJ Open 2016;6:e010415. 
17. Cammu EM H, Martens G, Van Mol C, et al. Perinatale activiteiten in Vlaanderen 2013, 2014. Retrieved fromAccessed on. https:// www.zorg-en-gezondheid.be/sites/default/files/atoms/files/SPE_ jaarrapport\%202013.pdf.

18. Cammu EM H, Martens G, Van Mol C, et al. Perinatale Activiteiten in Vlaanderen 2012, 2013. Retrieved fromAccessed on. https:// www.zorg-en-gezondheid.be/sites/default/files/atoms/files/SPE jaarrapport\%202012.pdf.

19. Van Leeuw VLC, Englert Y. Perinatale gegevens in het Brussels Gewest - Jaren 2013. Centre d'Epidémiologie périnatale, 2014. Retrieved fromAccessed on. http://www.cepip.be/pdf/rapport CEPIP_BxI2013_NL.pdf.

20. Leroy Ch VLV, Englert Y. Centre d'Epidémiologie Périnatale Données périnatales en Wallonie - Année 2013. 2014 http://www.cepip.be/pdf/ rapport CEPIP wallonie2013 tma.pdf (accessed on 22 December 16)

21. Armonk NIC. IBM SPSS Statistics for Windows, Version 22.0. In: Corp I, editor 2013.

22. Kayem G, Dupont $\mathrm{C}$, Bouvier-Colle $\mathrm{MH}$, et al. Invasive therapies for primary postpartum haemorrhage: a population-based study in France. BJOG 2016;123:598-605.

23. Colmorn LB, Krebs L, Langhoff-Roos J. NOSS study group. Potentially Avoidable Peripartum Hysterectomies in Denmark: A Population Based Clinical Audit. PLoS One 2016;11:e0161302.

24. Comstock $\mathrm{CH}$, Bronsteen RA. The antenatal diagnosis of placenta accreta. BJOG 2014;121:171-82.

25. D'Antonio F, lacovella $\mathrm{C}$, Bhide A. Prenatal identification of invasive placentation using ultrasound: systematic review and meta-analysis. Ultrasound Obstet Gynecol 2013;42:509-17.

26. Fitzpatrick KE, Sellers S, Spark P, et al. The management and outcomes of placenta accreta, increta, and percreta in the UK: a population-based descriptive study. BJOG 2014;121:62-71. discussion -1 .

27. Thurn L, Lindqvist PG, Jakobsson $M$, et al. Abnormally invasive placenta-prevalence, risk factors and antenatal suspicion: results from a large population-based pregnancy cohort study in the Nordic countries. BJOG 2016;123:1348-55.

28. Collins SL, Ashcroft A, Braun T, et al. Proposal for standardized ultrasound descriptors of abnormally invasive placenta (AIP). Ultrasound Obstet Gynecol 2016;47:271-5.

29. Chantraine F, Braun T, Gonser M, et al. Prenatal diagnosis of abnormally invasive placenta reduces maternal peripartum hemorrhage and morbidity. Acta Obstet Gynecol Scand 2013;92:439-44.

30. Eller AG, Bennett MA, Sharshiner M, et al. Maternal morbidity in cases of placenta accreta managed by a multidisciplinary care team compared with standard obstetric care. Obstet Gynecol 2011;117(2 Pt 1):331-7.
31. Placenta Accreta. The American College of Obstetricians and Gynaecologistis. Committee Opinion. Number 529. Published July 2012 Reaffirmed 2015.

32. Belfort MA. Publications Committee, Society for Maternal-Fetal Medicine. Placenta accreta. Am J Obstet Gynecol 2010;203:430-9.

33. Kayem G, Davy C, Goffinet F, et al. Conservative versus extirpative management in cases of placenta accreta. Obstet Gynecol 2004;104:531-6.

34. Sentilhes L, Ambroselli C, Kayem G, et al. Maternal outcome after conservative treatment of placenta accreta. Obstet Gynecol 2010;115:526-34.

35. Fox KA, Shamshirsaz AA, Carusi D, et al. Conservative management of morbidly adherent placenta: expert review. Am J Obstet Gynecol 2015;213:755-60.

36. Chantraine F, Nisolle M, Petit P, et al. Individual decisions in placenta increta and percreta: a case series. J Perinat Med 2012;40:265-70.

37. Dilauro MD, Dason S, Athreya S. Prophylactic balloon occlusion of internal iliac arteries in women with placenta accreta: literature review and analysis. Clin Radiol 2012;67:515-20.

38. Cali G, Forlani F, Giambanco L, et al. Prophylactic use of intravascular balloon catheters in women with placenta accreta, increta and percreta. Eur J Obstet Gynecol Reprod Biol 2014;179:36-41.

39. Duan $\mathrm{XH}$, Wang $\mathrm{YL}$, Han $\mathrm{XW}$, et al. Caesarean section combined with temporary aortic balloon occlusion followed by uterine artery embolisation for the management of placenta accreta. Clin Radiol 2015;70:932-7.

40. Sentilhes L, Gromez A, Clavier E, et al. Predictors of failed pelvic arterial embolization for severe postpartum hemorrhage. Obstet Gynecol 2009;113:992-9.

41. Poujade O, Zappa M, Letendre I, et al. Predictive factors for failure of pelvic arterial embolization for postpartum hemorrhage. Int $J$ Gynaecol Obstet 2012;117:119-23.

42. Yamasaki $\mathrm{Y}$, Morita $\mathrm{H}$, Miyahara $\mathrm{Y}$, et al. The factors associated with the failure of transcatheter pelvic arterial embolization for intractable postpartum hemorrhage. J Perinat Med 2014;42:359-62.

43. Touboul C, Badiou W, Saada J, et al. Efficacy of selective arterial embolisation for the treatment of life-threatening post-partum haemorrhage in a large population. PLoS One 2008;3:e3819.

44. Lee HJ, Jeon GS, Kim MD, et al. Usefulness of pelvic artery embolization in cesarean section compared with vaginal delivery in 176 patients. J Vasc Interv Radiol 2013;24:103-9.

45. Kim YJ, Yoon CJ, Seong NJ, et al. Failed pelvic arterial embolization for postpartum hemorrhage: clinical outcomes and predictive factors. J Vasc Interv Radiol 2013;24:703-9. 